Revista Perspectivas Online: Biológicas \& Saúde Julho de 2017, Vol.7, n' 24, p.88-95

ISSN: 2236-8868 (Online)

DOI: $10.25242 / 886872420171168$

\title{
DEGRADAÇÃO DE POLIURETANO POR FUNGOS: PERSPECTIVAS PARA PRESERVAÇÃO AMBIENTAL
}

\author{
Vicente Mussi-Dias ${ }^{1,2}$, Adão Valmir dos Santos ${ }^{3}$, Luana Pinto de Souza Tavares ${ }^{4}$, Glória Andreia \\ Ferreira Hernández ${ }^{4} \&$ Maria das Graças Machado Freire ${ }^{1 *}$
}

\begin{abstract}
RESUMO
MUSSI-DIAS, V.; SANTOS, A.V.; TAVARES, L.P.S.; HERNÁNDES, G.A.F. \& FREIRE, M.G.M. Degradação de poliuretano por fungos: perspectivas para preservação ambiental. Perspectivas Online: Biológicas e Saúde, v.7, n.24, p.88-95, 2017.

Alternativas buscando minimizar os problemas ambientais, sendo estas menos agressivas ao homem, têm sido foco de pesquisas realizadas no Laboratório de Química e Biomoléculas (LAQUIBIO)/ISECENSA. Possuidor de uma micoteca com quase dois mil fungos de restinga da região norte fluminense, podendo alguns destes, apresentarem-se promissores na biorremediação de diversos poluentes, como aqueles à base de poliuretano, um dos mais vendidos no mundo, que é descartado em grandes quantidades na natureza. Dessa forma, o objetivo deste trabalho foi desenvolver um meio de cultura

LAQUIBIO com capacidade de degradação de poliuretano. Para tal, foi preparado um meio de cultura com este polímero e 16 isolados de fungos foram cultivados e avaliados com relação à colonização de fragmentos de poliuretano. Observou-se o crescimento micelial de todos os fungos testados. No entanto, até o momento, apenas um isolado foi capaz de colonizar os fragmentos do polímero. Os resultados são promissores e novos ensaios devem ser conduzidos a fim de se detectar a produção enzimática degradadora de poliuretano por estes fungos.
\end{abstract} para a seleção de fungos da coleção biológica do

Palavras-chave: poliuretano, biorremediação, degradação fúngica. 


\begin{abstract}
Alternatives looking for minimize environmental problems, which are less harmful to man, have been the focus of research conducted in the Laboratory of Chemistry and Biomolecules (LAQUIBIO) / ISECENSA. The laboratory has a biological collection with almost two thousand fungi collected in an area of restinga vegetation in northern Fluminense, some of which may be promising in the bioremediation of several of several pollutants, especially those based on polyurethane. This plastic is discarded in large quantities in the environment and is considered one of the most sold plastics in the world. Thus,

the objective of this work was to develop a culture medium able to select fungi from the biological collection of the LAQUIBIO with ability to degrade polyurethane. Therefore, a culture medium containing this polymer was prepared and 16 fungal isolates were cultivated and evaluated for the colonization of polyurethane fragments. It was observed the mycelial growth of all fungi tested. However, only one fungal isolate was able to colonize the polymer fragments to date. These are promising results and further assays should be conducted in order to detect the polyurethane enzymatic degradation by these fungi.
\end{abstract}

Keywords: polyurethane, bioremediation, fungal degradation.

${ }^{1}$ Institutos Superiores de Ensino do CENSA - ISECENSA - Laboratório de Química e Biomoléculas - Rua Salvador Correa, 139, Centro, Campos dos Goytacazes, RJ, CEP: 28035-310, Brasil;

${ }^{2}$ Universidade Estadual do Norte Fluminense Darcy Ribeiro - UENF - Laboratório de Entomologia e Fitopatologia LEF/CCTA - Av. Alberto Lamego, 2000, Parque Califórnia, Campos dos Goytacazes, RJ, CEP: 28013-602, Brasil. ${ }^{3}$ Universidade Estadual do Norte Fluminense Darcy Ribeiro - UENF- Laboratório de Biotecnologia - LBT/CBB - Av. Alberto Lamego, 2000, Parque Califórnia, Campos dos Goytacazes, RJ, CEP: 28013-602, Brasil.

${ }^{4}$ Estagiárias do Laboratório de Química e Biomoléculas - Rua Salvador Correa, 139, Centro, Campos dos Goytacazes, RJ, CEP: 28035-310, Brasil

(*) e-mail: freire.mgm@gmail.com

Data de chegada: 19/04/2017 Aceito para publicação: 22/05/2017 


\section{INTRODUÇÃO}

O volume de plástico descartado como lixo tem aumentado de forma considerável nos últimos anos. Cerca de 25,2 milhões de toneladas desse lixo foi gerado somente na Europa em 2012 (PLASTICS EUROPE, 2013). No Brasil a geração total de lixo em 2013 foi de 76,3 milhões de toneladas. A Pesquisa Nacional de Saneamento Básico realizada em 2013 apontou que 62,1\% dos municípios declararam já dispor de alguma iniciativa para reciclagem de resíduos sólidos. Essa coleta, porém, ainda é ineficaz em qualidade e efetividade, dificultando a estimativa do percentual de plástico descartado no país (SCSSF, 2014). Apesar dos danos evidentes causados pelo descarte de plásticos no ambiente, a produção deste poluente ainda continua crescendo, principalmente nos países em desenvolvimento (RUSSELL et al., 2011).

Um destes materiais plásticos é o Poliuretano (PUR) que é um polímero derivado a partir da condensação de poli-isocianato e poliol, sendo amplamente utilizado como um material de base em várias indústrias (NAKAJIMA-KAMBE et al., 1999). O PUR tem sido usado na fabricação de mangueiras, calçados, enchimento de móveis e tecidos, isolante térmico e acústico, sendo considerado um dos plásticos mais vendidos no mundo (MARQUES \& MARTINS, 2009).

Diferentemente de outros plásticos, o PUR está frequentemente sujeito ao ataque de microorganismos, principalmente fungos de solo (BARRATT et al., 2003; DARBY \& KAPLAN, 1968) e, mais recentemente, RUSSELL et al. (2011) destacaram o papel promissor dos fungos endofíticos na degradação desse material. Alguns trabalhos indicam o potencial de fungos para a biodegradação de PUR quando são enterrados no solo (ZAFAR et al., 2013), uma vez que Cooney (1969) já havia demonstrado que a espuma de poliuretano poderia ser usada como uma matriz para a adesão do micélio do fungo. Esta suscetibilidade do Poliéster Poliuretano ao ataque de micro-organismos é facilitada devido à presença de ligações éster e uretano que são naturalmente vulneráveis à degradação enzimática (DARBY \& KAPLAN, 1968).

Fungos endofíticos têm sido isolados e identificados a partir de diferentes espécies vegetais com as mais variadas finalidades (LEGAUT et al., 1989; CLAY, 1993; SCHULZ et al., 1993; FISHER, 1996; GAMBOA et al., 2002; ARNOLD et al., 2003; SOUZA et al., 2004; ALMEIDA et al., 2005; MUSSI-DIAS et al., 2012), despertando o interesse da comunidade científica, pela aplicabilidade e utilização potencial de seus metabólitos, principalmente para fins industriais. Uma variedade de componentes químicos com propriedades farmacêuticas, cosméticas e agrícolas, tais como inseticidas, herbicidas e bactericidas (TAN \& ZOU, 2001; STROBEL \& DAYSE, 2003) tem sido desenvolvidos, além de outros compostos frequentemente testados como anticancerígenos, fontes alternativas de combustíveis e bioremedidores, este último ainda pouco explorado (LACAVA et al., 2010).

Segundo (RUSSELL et al., 2011) o fato de micro-organismos endofíticos ocuparem um nicho biológico único, o tecido de plantas, que é rico em complexo de polímeros de carbono, é uma justificativa para a investigação do potencial da ampla capacidade metabólica destes organismos. Trabalhos recentes têm focado na seleção de micro-organismos com habilidade de degradar polímeros sintéticos, objetivando a descoberta de possíveis novas enzimas.

Dessa forma, a partir de uma visão preservacionista voltada aos recursos naturais da região Norte Fluminense, uma fonte inesgotável de fungos endofíticos encontra-se disponível nas Restingas da região, das quais mais de 2000 isolados fúngicos já foram obtidos e encontram-se depositados na Micoteca do LAQUIBIO/ISECENSA para serem testados e utilizados em biorremediação. Assim, o objetivo desse trabalho foi desenvolver um meio de cultura para a seleção de fungos da coleção biológica do LAQUIBIO com capacidade para a degradação de poliuretano de origem vegetal.

Persp. online: biol. \& saúde, Campos dos Goytacazes, 24 (7), 88-95, 2017

seer.perspectivasonline.com.br 


\section{MATERIAL E MÉTODOS}

Ensaios foram realizados no LAQUIBIO/ISECENSA a partir da repicagem de fungos endofíticos das restingas do norte fluminense, os quais encontram-se armazenados em água destilada esterilizada no LAQUIBIO. Dezesseis diferentes isolados de fungos foram selecionados aleatoriamente para os testes iniciais da pesquisa, sendo eles identificados como: LAQUIBIO 5B1.1, LAQUIBIO 22A1, LAQUIBIO 24B2, LAQUIBIO 35C1, LAQUIBIO 38C3, LAQUIBIO 11A2, LAQUIBIO 5A2, LAQUIBIO 11A1, LAQUIBIO 32A2, LAQUIBIO 13B4, LAQUIBIO 17B3, LAQUIBIO 9A, LAQUIBIO 34C1, LAQUIBIO 20B, LAQUIBIO 15A2 E LAQUIBIO 7A2.

O meio de cultura padrão utilizado para a manutenção das colônias foi o Batata-dextrose-agar (BDA) e, para as análises de degradação, o meio adaptado de Cangemi, et al. (2008) e Darby e Kaplan (1968), sendo composto pelos sais $\mathrm{NaNO}_{3}, 3,0 \mathrm{~g} ; \mathrm{K}_{2} \mathrm{HPO}_{4}, 1,0 \mathrm{~g} ; \mathrm{MgSO}_{4} .7 \mathrm{H}_{2} \mathrm{O}, 0,25 \mathrm{~g} ; \mathrm{KCl}, 0,25 \mathrm{~g}$; extrato de levedura, 0,2 g, ágar $14 \mathrm{~g}$, polímero de óleo de mamona, 6,0 g; água destilada, 1,0 L (Meio SPU). Para o preparo do polímero foi utilizada uma espuma expansiva natural de poliueretano derivado do óleo de mamona (MAMONEX RD70) fornecido pela empresa IMPERVEG. A espuma foi preparada de acordo com as orientações do fabricante, misturando-se $50 \mathrm{~mL}$ de cada um dos dois componentes (Figura 1a). Em um Becker de $500 \mathrm{~mL}$, misturou-se a solução com um bastão de vidro e a reação expansiva proporcionou, em alguns segundos, a formação de uma espuma (Figura 1b). Após 24 h de repouso, a espuma solidificada foi cortada em pequenas partes, triturada em liquidificador e peneirada para obtenção de um pó fino (Figura 1c e 1d).

O polímero foi esterilizado separadamente e depois transferido para placa de Petri de forma proporcional ao volume do meio (Figura 1d). A seguir, verteu-se a fase líquida fundida (Figura 1e), agitandose frequentemente a suspensão para dispersar melhor os fragmentos do polímero no meio.

Cada isolado foi repicado em triplicata para o centro de placas contendo o meio de poliuretano que foram mantidas a $25{ }^{\circ} \mathrm{C}$ e fotoperíodo de $12 \mathrm{~h}$. As observações do desenvolvimento das colônias e as alterações no meio foram feitas diariamente por um período de 30 dias. 


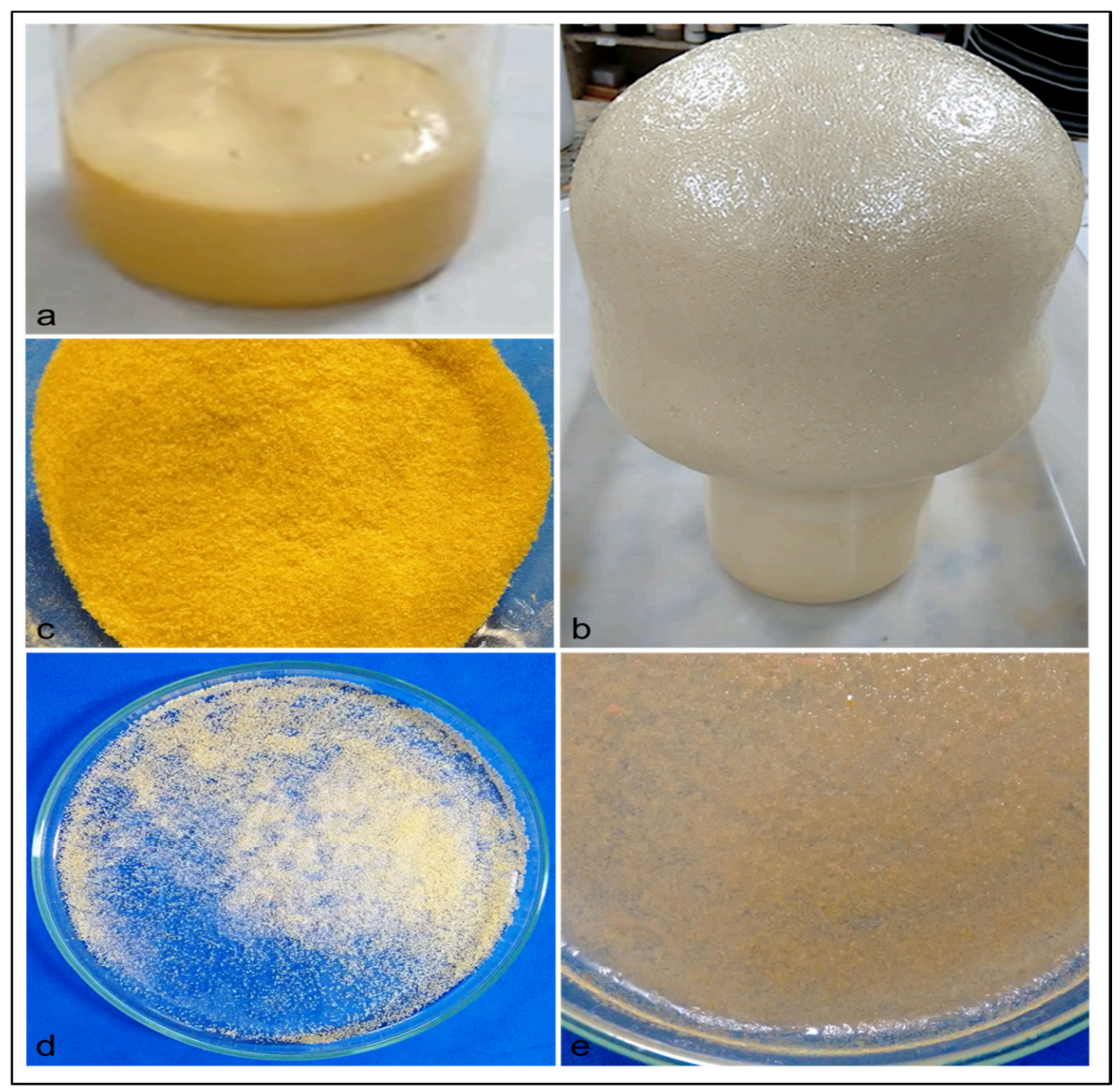

Figura 1. Etapas do preparo do meio de cultura para fungos contendo poliuretano. a) mistura liquida derivada de óleo de mamona associado ao polímero; b) espuma expansiva formada pela mistura após polimerização; c) poliuretano triturado e peneirado; d) porção do polímero autoclavado individualmente por placa de Petri antes da mistura ao meio de cultura fundente; e) meio solidificado em placa de Petri pronto para a repicagem de fungo.

\section{RESULTADOS E DISCUSSÃO}

Todos os fungos endofíticos de restinga utilizados nesta pesquisa, obtidos da Micoteca do LAQUIBIO, cresceram bem em meio SPU e exibiram suas características morfológicas típicas de cada gênero. Dessa forma, foi possível utilizá-los nos ensaios para a avaliação da colonização de fragmentos de poliuretano.

Em meio contendo o polímero (SPU) o crescimento vegetativo foi menor, quando comparado ao meio BDA, embora a produção de esporos e estruturas reprodutivas tenham sido induzidos para os fungos LAQUIBIO 5A2, LAQUIBIO 15A2 e LAQUIBIO 7A2 (Figura 2, letras g, o e p, respectivamente). 


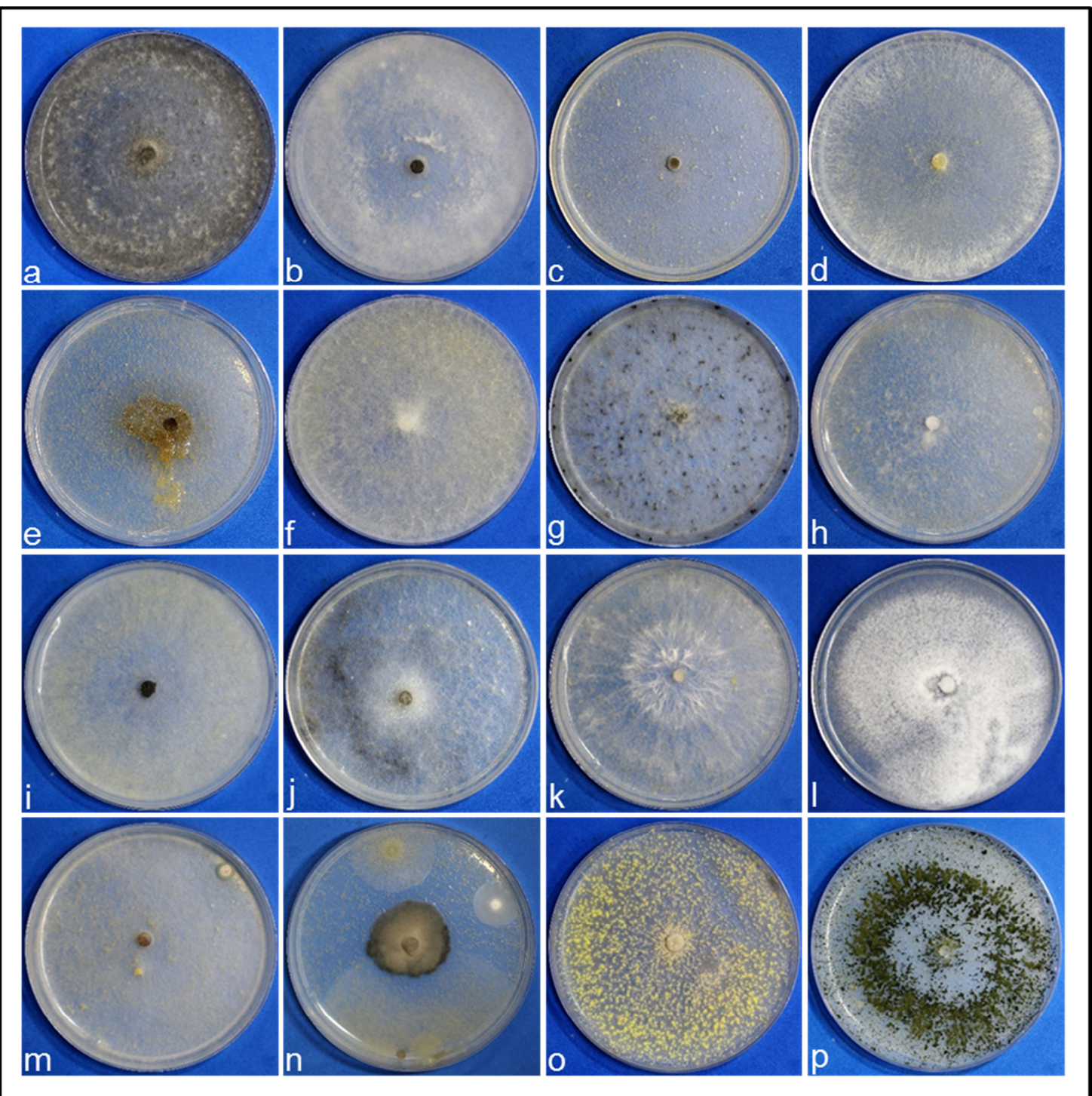

Figura 2. Colônias de fungos evidenciando o crescimento e esporulação em meio de cultura contendo poliuretano. a) LAQUIBIO 5B1.1, b) LAQUIBIO 22A1, c) LAQUIBIO 24B2, d) LAQUIBIO 35C1, e) LAQUIBIO 38C3, f) LAQUIBIO 11A2, g) LAQUIBIO 5A2, h) LAQUIBIO 11A1, i) LAQUIBIO 32A2, j) LAQUIBIO 13B4, k) LAQUIBIO 17B3, 1) LAQUIBIO 9A, m) LAQUIBIO 34C1, n) LAQUIBIO 20B, o) LAQUIBIO 15A2 e p) LAQUIBIO 7A2.

Um dos isolados, LAQUIBIO 5A2 foi capaz de colonizar os fragmentos do polímero incorporados ao meio (Figura 3), podendo ser comprovado através da observação do surgimento de hifas envolvendo as partículas de poliuretano (Figura 3b). Essa colonização pode ser um indicativo que este fungo seja hábil em utilizar o PU como nutriente, o que levaria à degradação das partículas do mesmo. De acordo com Cangemi et al. (2008) a degradação dos poliueretanos por micro-organismos pode ocorrer por efeito mecânico, bioquímico ou enzimático. 


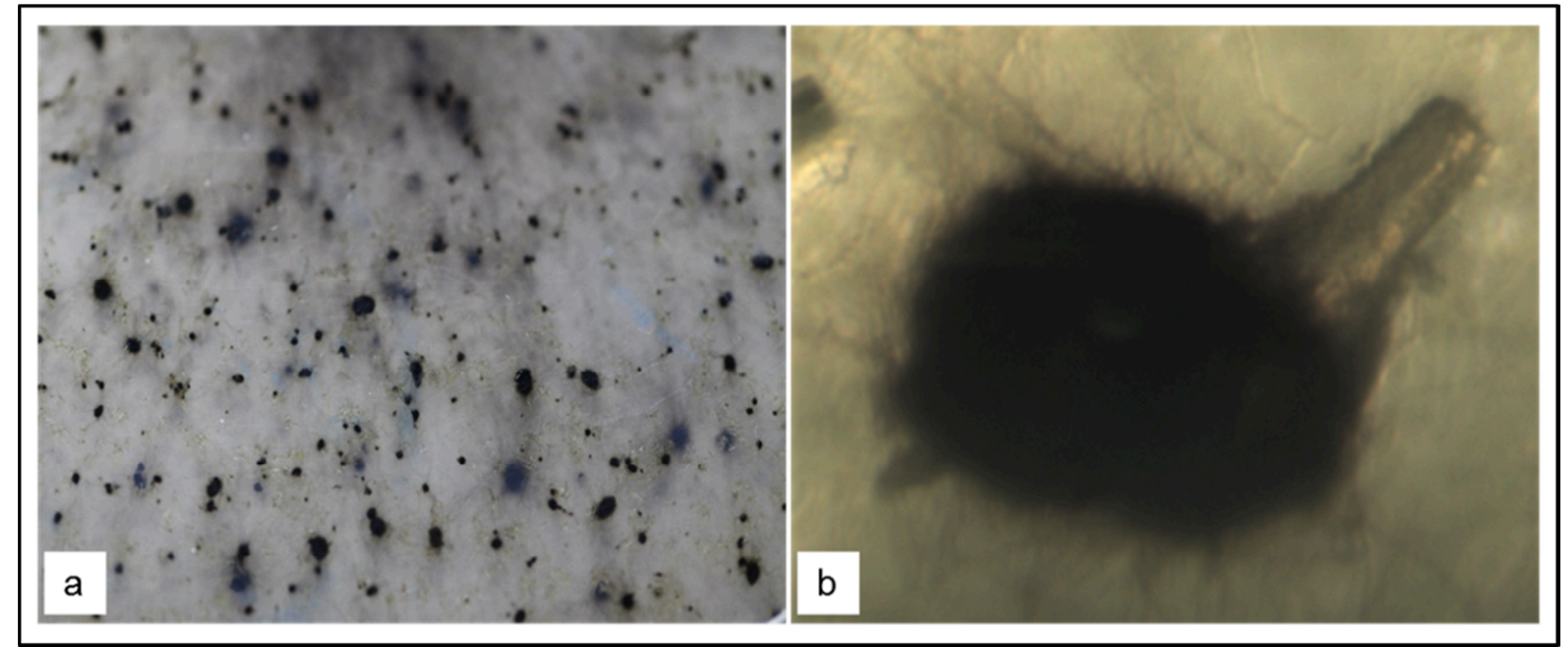

Figura 3. Crescimento de fungo e colonização de fragmento de poliuretano em meio de cultura. a) isolado LAQUIBIO 5A2 com crescimento sobre a superfície do meio e produção de estrutura de frutificação; b) colonização e enovelamento de hifas sobre fragmento de poliuretano.

\section{CONSIDERAÇÕES FINAIS}

Concluindo, os resultados iniciais apontam que será possível desenvolver metodologias de adequação para melhorar a seleção de fungos promissores na produção de enzimas degradadoras de poliuretano.

\section{REFERÊNCIAS}

ALMEIDA, C.V.; YARA, R.; ALMEIDA, M. Fungos endofiticos isolados de apices caulinares de pupunheira cultivada in vivo e in vitro. Pesquisa Agropecuária Brasileira, v. 40, n. 5, p. 467-470, 2005.

ARNOLD, A.E.; MEJIA, L.C.; KYLLO, D.; ROJAS, E.I.; MAYNARD, Z.; ROBBINS, N.; HERRE, E.A. Fungal endophytes limit pathogen damage in a tropical tree. Proceedings of the National Academy of Sciences, v. 100, n. 26, 2003.

BARRATT, S. R. et al. Fungi are the predominant micro-organisms responsible for degradation of soilburied polyester polyurethane over a range of soil water holding capacities. Journal of Applied Microbiology, v. 95, n. 1, p. 78-85, jul. 2003.

CANGEMI, J. M. et al. Biodegradation of polyurethane derived from castor oil. Polímeros, v. 18, n. 3, p. 201-206, 2008.

CLAY, K. The ecology and evolution of endophytes. Agriculture, Ecosystems and Environment, v. 44, n. 14, p. 39-64, 1993.

COONEY, J. J. Effects of polyurethane foams on microbial growth in fuel-water systems. Applied microbiology, v. 17, n. 2, p. 227-31, 1969.

DARBY, R. T.; KAPLAN, A M. Fungal susceptibility of polyurethanes. Applied microbiology, v. 16, n. 6, p. 900-905, 1968.

FISHER, P.J. Survival e spread of the endophyte Stagnospora pteridiicola in Pteridium aquilinum, other ferns and some flowering plants. New Phytologist, v. 132, n. 1, p. 119-122, 1996. 
GAMBOA, M.A.; LAUREANO, S.; BAYMAN, P. Measuring diversity of endophytic fungi in leaf fragments: Does size matter? Mycopathologia, v. 156, p. 41-45, 2002.

LACAVA, P.T.; SEBASTIANES, F.L.S.; AZEVEDO, J.L. Fungos endofiticos: biodiversidade e aplicações biotecnologicas. In: ESPOSITO, E.; AZEVEDO, J.L. (Orgs.). Fungos: uma introdução à biologia, bioquímica e biotecnologia. 2 ed., Caxias do Sul: Educs, 2010. 638 p.

LEGAUT, D.; DESSUREALT, M.; LAFRLAMME, G. Mycoflore des aiguilles de Pinus banksiana et Pinus resinosa I. Champignons endophytes. Canadian Journal of Botany, v. 67, p. 2052-2060, 1989.

MARQUES, B. R.; MARTINS, L. J. R. Poliuretano derivado de óleo de mamona: de Meio Ambiente a Biocopatibilidade. 2009. Disponível em: http://www.unisalesiano.edu.br/encontro2009/trabalho/aceitos/CC36939464859.pdf $>$. Acesso em: 16 de abril de 2016.

MUSSI-DIAS, V.; ARAUJO, A.C.O.; SILVEIRA, S.F.; ROCABADO, J.M.A.; ARAUJO, K.L. Fungos endofiticos associados a plantas medicinais. Revista Brasileira de Plantas Medicinais, v. 14, n. 2, p. 261-266, 2012.

NAKAJIMA-KAMBE, T. et al. Microbial degradation of polyurethane, polyester polyurethanes and polyether polyurethanes. Applied Microbiology and Biotechnology, v. 51, n. 2, p. 134-140, 25 fev. 1999.

PLASTICS EUROPE. Plastics - the Facts 2013: An analysis of European latest plastics production, demand and waste data. Disponível em: <http://www.plasticseurope.org/documents/document/20131014095824final_plastics_the_facts_2013_published_october2013.pdf>. Acesso em: 16 maio. 2016.

RUSSELL, J. R. et al. Biodegradation of polyester polyurethane by endophytic fungi. Applied and Environmental Microbiology, v. 77, n. 17, p. 6076-6084, 2011.

SCHULZ, B.; WANKE, U.; DRAEGER, S.; AUST., H.J. Endophytes from herbaceous plants and shrubs: effectiveness of surface sterilization methods. Mycological Research, v. 97, p.1447- 1450, 1993.

SCSSF - SECRETARIA DE COMUNICAÇÃO SOCIAL DO SENADO FEDERAL. Brasil ainda coleta mal e recicla pouco o lixo. Revista em Discussão. Ano 5 - $\mathrm{N}^{\mathrm{o}} 22$ - setembro de 2014. Disponível em: http://www.senado.gov.br/noticias/jornal/emdiscussao/residuos-solidos/residuos-solidos.pdf. Acesso em: 18 de maio de 2017.

SOUZA, A.Q.L.; SOUZA, A.D.L.; FILHO, S.A.; PINHEIRO, M.L.B. SARQUIS, M.I.M., PEREIRA, J.O. Atividade antimicrobiana de fungos endofiticos isolados de plantas toxicas da Amazonia: Palicourea longiflora (aubl.) Rich e Strychnos cogens Bentham. Acta Amazonica, v. 34, n. 2, p.185 -195, 2004.

STROBEL, G.A.; DAISY, B. Bioprospecting for microbial endophytes and their natural products. Microbiology and Molecular Biology Reviews, v. 67, n. 4, p. 491-502, 2003.

TAN, R.X.; ZOU, W.X. Endophytes: a rich source of functional Metabolites. Nat. Prod. Rep., 18, 448-459. 2001.

ZAFAR, U.; HOULDEN, A.; ROBSON, G. D. Fungal communities associated with the biodegradation of polyester polyurethane buried under compost at different temperatures. Applied and environmental microbiology, v. 79, n. 23, p. 7313-24, dez. 2013. 